Article

\title{
Simultaneous Determination of AFB1 and AFM1 in Milk Samples by Ultra High Performance Liquid Chromatography Coupled to Quadrupole Orbitrap Mass Spectrometry
}

\author{
Yelko Rodríguez-Carrasco ${ }^{1, *(1)}$, Luana Izzo ${ }^{2}$ (D), Anna Gaspari ${ }^{2}$, Giulia Graziani ${ }^{2}$, Jordi Mañes ${ }^{1}$ \\ and Alberto Ritieni ${ }^{2}$ \\ 1 Department of Food Science and Toxicology, Faculty of Pharmacy, University of Valencia, Av. Vicent Andrés \\ Estellés s/n, 46100 Burjassot, Valencia, Spain; jordi.manes@uv.es \\ 2 Department of Pharmacy, University of Naples Federico II, Via Domenico Montesano 49, 80131 Naples, Italy; \\ luana.izzo@unina.it (L.I.); annagaspari@virgilio.it (A.G.); giulia.graziani@unina.it (G.G.); \\ alberto.ritieni@unina.it (A.R.) \\ * Correspondence: yelko.rodriguez@uv.es; Tel.: +34-354-4117
}

Received: 7 May 2018; Accepted: 6 June 2018; Published: 8 June 2018

\begin{abstract}
Milk is the world's most consumed beverage, not counting water. Even though investigations on milk aflatoxin (AF) M1 contamination are regularly conducted, there is limited information on the contamination of milk with its parent compound, AFB1. Hence, the aim of this study was to develop a quick, easy, cheap, effective, rugged, and safe (QuEChERS)-based method for the simultaneous analysis of AFB1 and AFM1 in milk, using ultrahigh performance liquid chromatography coupled with high resolution mass spectrometry (UHPLC-Q-Orbitrap HRMS). The recoveries were in a range of $75-96 \%$ at $0.005,0.01$, and $0.05 \mu \mathrm{g} / \mathrm{L}$ spiking levels, with repeatability and reproducibility results expressed as relative standard deviations (RSDs) lower than $7 \%$ and $16 \%$, respectively. The limits of detection (LODs) and quantification (LOQs) were 0.001 and $0.002 \mu \mathrm{g} / \mathrm{L}$ for AFM1 and AFB1, respectively. The LODs and LOQs that were obtained showed the suitability of the developed method for the determination of trace amounts of the selected mycotoxins in milk samples, and were up to ten times lower than those that had been reported in previous works using triple quadrupole mass analyzers. The matrix effect was evaluated and matrix-matched calibrations were used for quantification. The validated method was applied to 40 Italian milk samples. Neither AFB1 nor AFM1 were found above the LOD in any of the analyzed samples.
\end{abstract}

Keywords: aflatoxin M1; aflatoxin B1; milk; mass spectrometry; QuEChERS; Orbitrap HRMS

\section{Introduction}

Mycotoxins are secondary toxic metabolites that are produced by several species of fungi, mainly belonging to the Aspergillus, Penicillium, Alternaria, and Fusarium genera. These fungi are able to contaminate agricultural products and to produce mycotoxins under favorable conditions [1]. Contamination of food and feed with mycotoxins is a worldwide problem. In fact, the Food and Agriculture Organization (FAO) has estimated that a quarter of the world's crops are contaminated with mycotoxins, and it has a major economic impact [2]. Moreover, mycotoxins are of significant public health concern, based on their high toxic profile. Among these contaminants some metabolites of Aspergillus flavus and Aspergillus parasiticus, namely aflatoxins (AFs), can be found, which are classified as carcinogenic to humans (Group 1) by the International Agency for Research on Cancer (IARC) [3]. Hence, it is appropriate to keep the levels for AFs as low as reasonably achievable in both 
food and feed. In this sense, the Commission Directive 2003/100/EC set a maximum content of AFB1 of $20 \mu \mathrm{g} / \mathrm{kg}$ in all feed materials, with the exception of complete feeding stuffs for dairy animals, which has been reduced by up to $5 \mu \mathrm{g} / \mathrm{kg}$ [4]. AFM1 is the principal hydroxylated AFB1 metabolite that is present in the milk of cows that are fed with AFB1-contaminated feed, and it was classified as possibly carcinogenic to humans (Group 2B) by IARC. [5]. This metabolite is thermally resistant and is not completely inactivated after pasteurization, sterilization, or other milk treatment processes, and thus could represent a public health concern [6]. Consequently, the Commission Regulation (EC), No. 165/2010, and amending Regulation (EC), No. 1881/2006, with regards to aflatoxins, set the most restrictive limits for AFM1 content in milk at $0.05 \mu \mathrm{g} / \mathrm{kg}$ for raw milk, heat-treated milk, and milk for the manufacture of milk-based products, and of up to $0.025 \mu \mathrm{g} / \mathrm{kg}$ for infant formulae and follow-on formulae, including infant milk and follow-on milk [7].

Milk is the world's most consumed beverage, not counting water, and it is the primary source of nourishment for the normal growth of infants and children. According to the latest data that were reported by FAO, the European population has a significantly higher milk and dairy consumption than the global population, with an annual per capita data of $236.4 \mathrm{~kg}$ and $90 \mathrm{~kg}$, respectively. Among the European countries, Italy is one of the highest milk and dairy consumers, with an annual per capita consumption of $246.9 \mathrm{~kg}$ [8]. On the other hand, the complexity of milk composition, containing fat, proteins, sugar, and other components, makes sample treatment difficult and, usually, different cleanup steps are necessary after extraction. Besides solid-phase extraction [9], liquid-phase extraction [10], and immunoaffinity column assay [11] for the purification and enrichment, QuEChERS (acronym for quick, easy, cheap, effective, rugged and safe) was a significant method for high-throughput determination and has been widely employed for the analysis of mycotoxins in different matrices [12-15], including milk [16,17]. Most of the studies regarding the occurrence of mycotoxins in milk are only focused on AFM1 analysis. Nevertheless, in recent years, the number of reports of milk being contaminated by multiple mycotoxins has increased, raising concerns about whether the synergistic effects of these coexisting mycotoxins could affect public health. In this sense, not much literature has considered evaluating the occurrence of AFB1 in milk, despite the fact that it is a carcinogenic compound to humans [18-20]. For instance, a recent study reported an incidence of AFB1 and AFM1 in $12.4 \%$ and $98.8 \%$, respectively, of Chinese milk samples $(n=250)$ [21]. Therefore, humans are potentially exposed to these toxic metabolites and it becomes necessary to take a vigilant attitude in order to minimize the human intake of aflatoxins. To achieve this purpose, analytical methods must provide enough sensibility to reach the maximum limits that have been set by the Commission Regulation. In this sense, liquid chromatography mass spectrometry (LC-MS) methods, for multi-mycotoxin analysis in milk, have been reported in the literature $[6,22,23]$. In recent years, there has been increasing interest in evaluating the capability of the high-resolution mass spectrometry (HRMS) for multi-mycotoxin analysis because it provides not only a high resolution and accuracy mass results, but also a high sensibility and complementary structural information when compared with other MS detectors [21,24].

According to the aforementioned information, this method includes the analysis of AFM1 and its parent compound, AFB1, the latter having not been being frequently studied in milk. This method, with a simple extraction procedure based on the QuEChERS method, coupled with the high throughput determination that was provided by the ultrahigh performance liquid chromatography Q-Orbitrap mass spectrometry, has been successfully validated and applied to the analysis of these toxic compounds in 40 commercially available milk samples from Italy.

\section{Materials and Methods}

\subsection{Chemicals and Materials}

Acetonitrile, methanol, and water (LC-MS grade) were purchased from Merck (Darmstadt, Germany). Formic acid (mass spectrometry grade) and ammonium formate (analytical grade) were 
obtained from Fluka (Milan, Italy). Syringe filters with polytetrafluoroethylene membrane (PTFE, $15 \mathrm{~mm}$, diameter $0.2 \mu \mathrm{m}$ ) were supplied by Phenomenex (Castel Maggiore, Italy).

Sodium chloride and anhydrous sulphate sodium were acquired from Sigma Aldrich (Milan, Italy). Primary secondary amine (PSA) sorbent and C18 (analytical grade) were purchased from Supelco (Bellefonte, PA, USA). Standards of AFB1 and AFM1 (purity $>98 \%$ ) were acquired from Sigma Aldrich (Milan, Italy). Individual standard solutions of AFM1 and AFB1 were prepared at $1 \mu \mathrm{g} / \mathrm{mL}$ in methanol. Working standard solutions at 5,10 , and $50 \mu \mathrm{g} / \mathrm{L}$ were prepared by adequate dilutions of the stock, for the spiking experiments. All solutions were stored at $-20{ }^{\circ} \mathrm{C}$ in screw-capped glass vials.

\subsection{Sampling}

A total of 40 milk samples were randomly purchased between January and February 2018, from different supermarkets located in the Campania region, Southern Italy. The samples were shipped to the laboratory in their original packages and stored at $4{ }^{\circ} \mathrm{C}$ until analysis. The milk analysis was carried out within two days after the arrival of the samples.

\subsection{Sample Preparation}

A QuEChERS-based procedure for the extraction of mycotoxins in milk was employed as a starting point, with minor modifications [16]. In short, $10 \mathrm{~mL}$ of sample was introduced into a $50 \mathrm{~mL}$ Falcon tube and $2.5 \mathrm{~mL}$ of distillate water, and $5 \mathrm{~mL}$ of acetonitrile, containing $3.35 \%$ of formic acid, $(v / v)$ was added. The mixture was vortexed vigorously for $2 \mathrm{~min}$ and then subjected to ultrasonic extraction for $15 \mathrm{~min}$ (vortexed in every $5 \mathrm{~min}$ interval). After that, the tube involved the addition of $4.0 \mathrm{~g}$ of sulphate sodium anhydrous and $1.2 \mathrm{~g}$ of sodium chloride, which was shaken by hand for $2 \mathrm{~min}$ and then centrifuged for $3 \mathrm{~min}$ at $4000 \mathrm{rpm}$ and $4{ }^{\circ} \mathrm{C}$. The upper organic layer was transferred to a $15 \mathrm{~mL}$ Falcon tube containing $300 \mathrm{mg}$ of C18 sorbent, $140 \mathrm{mg}$ of PSA, and $1.5 \mathrm{~g}$ of sulphate sodium. The mixture was vortexed for $1 \mathrm{~min}$ and was then centrifuged for $1 \mathrm{~min}$ at $1500 \mathrm{rpm}$ and $4{ }^{\circ} \mathrm{C}$. The supernatant was transferred into a new glass tube and then evaporated under a gentle nitrogen flow at $45^{\circ} \mathrm{C}$. Finally, the residue was reconstituted with $500 \mu \mathrm{L}$ of $\mathrm{MeOH}: \mathrm{H}_{2} \mathrm{O}(70: 30, v / v)$, filtered $(0.22 \mu \mathrm{m}$ membrane filter), and transferred into a vial for UHPLC-Q-Orbitrap HRMS analysis. Figure 1 shows the schematic flow of the sample preparation procedure.

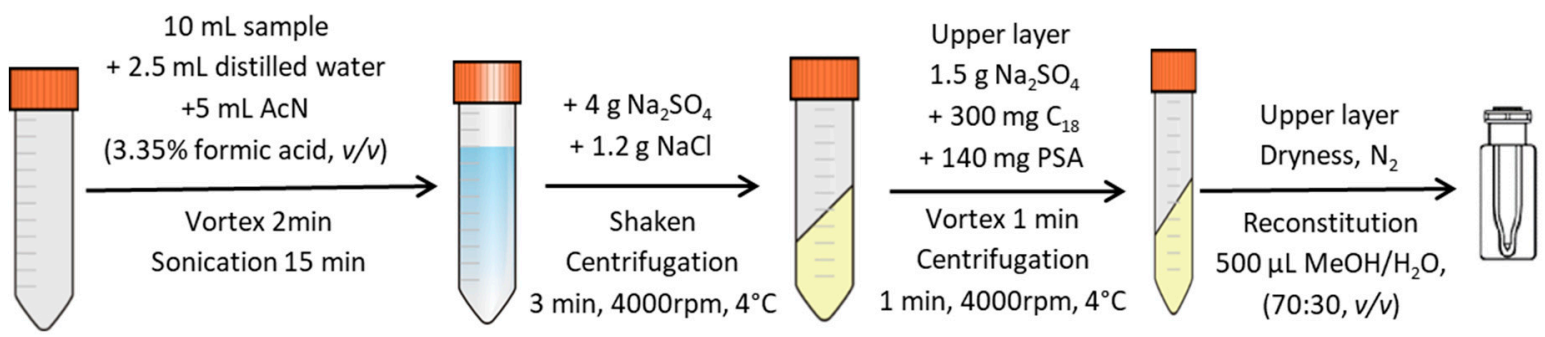

Figure 1. Schematic flow of the sample preparation procedure.

\subsection{UHPLC-Q-Orbitrap HRMS Analysis}

The analyses were performed using an UHPLC instrument (Dionex Ultimate 3000, Thermo Fisher Scientific, Waltham, MA, USA) coupled with a Q Exactive Orbitrap mass spectrometer (UHPLC, Thermo Fischer Scientific, Waltham, MA, USA). The UHPLC system consisted of a degassing system, a Quaternary UHPLC pump working at 1250 bar, an auto sampler device, and a thermostated Luna Omega column $\left(50 \times 2.1 \mu \mathrm{m}, 1.6 \mu \mathrm{m}\right.$, Phenomenex) that was held at $30^{\circ} \mathrm{C}$. The mobile phases were as follows: phase A, water with $0.1 \%$ formic acid and $5 \mathrm{mM}$ ammonium formate; and phase $\mathrm{B}$, methanol with $0.1 \%$ formic acid and $5 \mathrm{mM}$ ammonium formate. A linear gradient elution program was applied as follows: initially $0 \% \mathrm{~B}$ was held for $1 \mathrm{~min}$ and then increased to $95 \% \mathrm{~B}$ in $1 \mathrm{~min}$, and held for $0.5 \mathrm{~min}$. Then, the gradient was linearly decreased to $75 \%$ in $2.5 \mathrm{~min}$, and decreased again to $60 \% \mathrm{~B}$ in $1 \mathrm{~min}$. 
After that, the gradient was reduced to $0 \%$ in $0.5 \mathrm{~min}$ and was held for $1.5 \mathrm{~min}$ for re-equilibration, giving a total run time of $8 \mathrm{~min}$. The flow rate was $0.4 \mathrm{~mL} / \mathrm{min}$ and the injection volume was $5 \mu \mathrm{L}$. The detection was performed using a Q-Exactive mass spectrometer [25].

The mass spectrometer was operated in positive ion mode by setting two scan events (full ion MS and all ion fragmentation [AIF]). Full scan data in positive mode were acquired at a resolving power of 70,000 FWHM at $200 \mathrm{~m} / z$. The conditions in the positive ionization mode (ESI+) were as follows: spray voltage $4000 \mathrm{~V}$; capillary temperature $290{ }^{\circ} \mathrm{C}$; S-lens $\mathrm{RF}$ level 50 ; sheath gas pressure $\left(\mathrm{N}_{2}>95 \%\right)$ 35 ; auxiliary gas $\left(\mathrm{N}_{2}>95 \%\right) 10$; and auxiliary gas heater temperature $305^{\circ} \mathrm{C}$. The mass range in the full scan experiments was set at $m / z 100-1000$. The parameters in the positive ion mode for the scan event of AIF were as follows: mass resolving power $=10,000 \mathrm{FWHM}$; scan time $=0.10 \mathrm{~s} ; \mathrm{HCD}$ collision energy $=30 \mathrm{eV}$. UHPLC-HRMS parameters of the studied mycotoxins are shown in Table 1 . The data analysis and processing were evaluated by the Quan/Qual Browser Xcalibur software, v. 3.1.66. (Xcalibur, Thermo Fisher Scientific, Waltham, MA, USA).

Table 1. Ultrahigh performance liquid chromatography coupled with high resolution mass spectrometry (UHPLC-HRMS) parameters of the studied mycotoxins.

\begin{tabular}{|c|c|c|c|c|c|c|c|c|}
\hline Mycotoxins & $\begin{array}{l}\text { Retention } \\
\text { Time (min) }\end{array}$ & $\begin{array}{l}\text { Elemental } \\
\text { Composition }\end{array}$ & Adduct Ion & $\begin{array}{l}\text { Theoretical } \\
\text { Mass }(m / z)\end{array}$ & $\begin{array}{c}\text { Measured } \\
\text { Mass }(m / z)\end{array}$ & $\begin{array}{l}\text { Accuracy } \\
(\Delta \text { ppm })\end{array}$ & $\begin{array}{l}\text { Product } \\
\text { Ion }(m / z)\end{array}$ & $\begin{array}{c}\text { Collision } \\
\text { Energy } \\
(\mathrm{eV})\end{array}$ \\
\hline AFM1 & 4.60 & $\mathrm{C}_{17} \mathrm{H}_{12} \mathrm{O}_{7}$ & {$[\mathrm{M}-\mathrm{H}]^{+}$} & 329.06558 & 329.06511 & -1.43 & $\begin{array}{l}273.07538 \\
229.04909\end{array}$ & 40 \\
\hline AFB1 & 5.02 & $\mathrm{C}_{17} \mathrm{H}_{12} \mathrm{O}_{6}$ & {$[\mathrm{M}-\mathrm{H}]^{+}$} & 313.07066 & 313.06958 & -3.45 & $\begin{array}{l}285.07489 \\
269.04373\end{array}$ & 36 \\
\hline
\end{tabular}

\subsection{Validation of the Method}

The validation of the method was carried out according to the EU Commission Decision 2002/657/EC [26]. The method performance was evaluated by the following parameters: linearity, matrix effect, trueness, precision, specificity, and sensitivity. All of the parameters were performed in triplicate.

Student $t$-test statistical analysis was performed for data evaluation: $p$ values $<0.05$ were considered significant.

\subsection{Quality Assurance/Quality Control (QA/QC) in the Analysis of Real Samples}

For the confirmation criteria, the retention times of the aflatoxins in the standards and samples were compared at a tolerance of $\pm 2.5 \%$ and an accurate mass $<5 \mathrm{ppm}$, thus providing a higher level of confidence in the analyses identification. In order to demonstrate the effectiveness of the validated method, a reagent blank, a procedural blank, a replicate sample, and a matrix-matched external calibration were included in each batch of samples for QA/QC. The fortified milk samples with AFB1 and AFM1 at three concentration levels $(0.005,0.01$, and $0.05 \mu \mathrm{g} / \mathrm{L})$ were used for analytical quality control (QC). The QC samples were stored and refrigerated at $4{ }^{\circ} \mathrm{C}$.

\section{Results and Discussion}

\subsection{Analytical Features of the Proposed Method}

The method validation was performed in-house for the determination of AFM1 and AFB1 in milk samples. Table 2 shows the performance of the proposed method, namely, linearity, matrix effect, trueness, precision, specificity and sensitivity. 
Table 2. Method performance.

\begin{tabular}{|c|c|c|c|c|c|c|c|}
\hline \multirow{2}{*}{ Parameters } & \multirow{2}{*}{$R^{2}$} & \multirow{2}{*}{ SSE (\%) } & \multicolumn{3}{|c|}{ Recovery, \% $\left(U^{\prime}, \% ; k=2\right)$} & \multirow{2}{*}{ LOD $(\mu \mathrm{g} / \mathrm{L})$} & \multirow{2}{*}{ LOQ $(\mu \mathrm{g} / \mathrm{L})$} \\
\hline & & & $0.005 \mu \mathrm{g} / \mathrm{L}$ & $0.01 \mu \mathrm{g} / \mathrm{L}$ & $0.05 \mu \mathrm{g} / \mathrm{L}$ & & \\
\hline AFM1 & 0.9994 & 65 & $75(26)$ & $84(20)$ & 91 (16) & 0.001 & 0.002 \\
\hline AF B1 & 0.9996 & 72 & $81(32)$ & $87(24)$ & $96(22)$ & 0.001 & 0.002 \\
\hline
\end{tabular}

$R^{2}$-correlation coefficients; SSE-signal suppression or enhancement; $U^{\prime}$-expanded uncertainty $(k=2)$; LOD—limit of detection; LOQ-limit of quantification.

\subsubsection{Linearity}

Linearity was evaluated using both the standard solutions and matrix-matched calibrations at six concentrations levels, ranging from 0.002 to $20 \mu \mathrm{g} / \mathrm{L}$. Calibration curves were performed in triplicate. The correlation between the response and the amount of analyte was verified by plotting signal intensity against analyte concentration. The correlation coefficients $\left(R^{2}\right)$ of both analytes was $>0.9990$.

\subsubsection{Matrix Effect}

The matrix effect (signal suppression or enhancement, SSE) was expressed as the ratio percentage between the slope of the matrix-matched calibration curve (A) and the curve in solvent (B). Thus, the ratio $(\mathrm{A} / \mathrm{B} \times 100)$ was defined as the matrix effect $(\%)$. A value of $100 \%$ indicated that there was no matrix effect. There was signal suppression if the value was lower than $100 \%$ and a signal enhancement if the value was higher than 100\%. The matrix effects for AFB1 and AFM1 were $72 \%$ and $65 \%$, respectively. Based on the results that were obtained, the matrix-matched calibrations were used for quantification purpose.

\subsubsection{Trueness and Precision}

The trueness was assessed throughout the addition of known amounts of the studied mycotoxins at $0.005,0.01$, and $0.05 \mu \mathrm{g} / \mathrm{L}$ to a blank milk sample, and were expressed as the percentage of recovery. The method provided satisfactory recoveries at each fortification level, ranging from $75 \%$ to $96 \%$ in all of the spiking levels, which were in agreement with the accepted values that were set at Commission Decision 2002/657/EC. The precision of the method was carried out by repeated measurements of the fortification levels that reported above, on the same day (repeatability, $n=3$ ) and on three different days (reproducibility, $n=3$ ), and were expressed as relative standard deviation ( $\%$ RSD). The precision data showed that the method was repeatable $(\mathrm{RSD}<7 \%$ ) and reproducible $(\mathrm{RSD}<16 \%)$. On the other hand, it was a requirement under ISO/IEC 17025 that laboratories determined and made available the expanded measurement uncertainty, which was associated with analytical results [27]. An expanded coverage factor of $k=2$ was usually assumed to calculate the expanded measurement uncertainty that was represented by $u^{\prime}$, from the relative standard uncertainty $u^{\prime}$ in Equation (1), as follows:

$$
U^{\prime}=k \times u^{\prime}
$$

The relative standard uncertainty $u^{\prime}$ was calculated using the laboratory reproducibility relative standard deviation combined with the estimated method bias, applying Equation (2), as follows:

$$
u^{\prime}=\sqrt{u^{\prime}\left(R S D_{R}\right)^{2}+u^{\prime}(\text { bias })^{2}}
$$

where: $u^{\prime}$ is the combine standard uncertainty; $u^{\prime}\left(R S D_{R}\right)$ is the laboratory reproducibility; and $u^{\prime}$ (bias) is the uncertainty component arising from method bias.

\subsubsection{Specificity}

A blank milk extract, from a sample that was previously analyzed to confirm the absence of target aflatoxins, was injected 10 times to study the signals that were obtained from the matrix, and to 
evaluate the possible sample interferences. The good specificity of the HRMS made it possible to have no signal interferences in the blank matrix for any of the studied aflatoxins.

\subsubsection{Limits of Detection and Limits of Quantification}

Sensitivity was evaluated by limit of detection (LOD) and limit of quantification (LOQ). The LOD was defined as the minimum concentration, where the molecular ion could be identified with a mass error below $5 \mathrm{ppm}$, and the LOQ were set as the lowest concentration of the analyte that produced a chromatographic peak with a precision and accuracy $<20 \%$. The method LODs and LOQs obtained were 0.001 and $0.002 \mu \mathrm{g} / \mathrm{kg}$, respectively. The LODs and LOQs that were obtained showed the suitability of the developed methods for the determination of trace amounts of the selected mycotoxins in the milk samples. In addition, the LOQs that were obtained here were up to 10 times lower than those that were reported by other authors using triple quadrupole mass analyzer, and were similar than those that were reported in a recent studies employing HRMS [21] (Table 3). Nevertheless, this last study used immunoaffinity columns, which significantly increase thed sample preparation procedure in terms of time and cost, compared with the inexpensive QuEChERS.

\subsubsection{QA/QC}

The quality of results were controlled through all of the experiments. The spiked matrix was used in the QA/QC procedure to properly evaluate the accuracy and precision of the proposed methodology. In order for the data to be acceptable, the following QA/QC criteria had to be met. Extraction was considered as conducted correctly when the recoveries were in the range from $70 \%$ and $120 \%(\mathrm{RSD}<20 \%)$. Out of this range, the extractions were repeated to meet these criterions.

\subsection{Application to Samples}

The validated UHPLC-Q-Orbitrap HRMS methodology was applied to 40 milk samples that were commercially available in Italy. The results showed that any analyzed sample was contaminated with AFM1 (LOD: $0.001 \mu \mathrm{g} / \mathrm{L}$ ). The data that were reported here were in agreement with previous monitoring studies carried out in the milk from European countries, in which the absence or low AFM1 incidence was reported. For instance, Tsiplakou et al. [22] did not find AFM1 (LOQ: $0.002 \mu \mathrm{g} / \mathrm{L}$ ) in any of the 21 milk analyzed samples from Greece. Similar results were recently reported by Flores-Flores et al. [20], who conducted a monitoring of AFM1 in tSpanish milk samples $(n=191)$, but none of them showed mycotoxin contamination (LOD: $0.025 \mu \mathrm{g} / \mathrm{L}$ ). In France, Boudra et al. [28] reported that $3.4 \%$ of the analyzed milk samples $(n=264)$ were contaminated with AFM1, but at levels below the EU regulation. In contrast, $1.6 \%$ of Croatian milk samples $(n=61)$ [29] and 5\% of Portuguese milk samples $(n=40)$ [30] presented AFM1 values that surpassed the legal maximum limit $(0.05 \mu \mathrm{g} / \mathrm{L})$. Despite that, Flores-Flores et al. [31] reviewed the occurrence of AFM1 in milk samples worldwide and reported that the European milk samples that exceeded the maximum EU limit $(0.9 \%, n=13566)$ were significantly lower than the milk samples that were commercialized in America $(8.6 \%, n=1267)$, Africa $(25.8 \%, n=980)$, and Asia $(26.7 \%, n=6376)$. Hence, Europeans seemed to be less exposed to AFM1 through milk consumption than other populations, and it could be probably related to the restrictive rules for AFM1 contamination in milk that were adopted by the EU (up to 10-fold lower than some countries).

Even though investigations on milk AFM1 contamination have been regularly conducted by European Economic Community (ECC) countries, there was limited information on the contamination of this food matrix by other major mycotoxins, such as AFB1. The existence of AFB1 in milk may have been as a result of contaminated feedstuffs that were not completely metabolized by the cow to AFM1, thus AFB1 was excreted in the milk. Table 3 summarizes the available studies focused on the occurrence of AFB1 and its metabolite AFM1 in milk samples. The occurrence of AFB1 was reported in $1.2 \%(n=80)$ [32], 1.4\% $(n=290)$ [33], 12.4\% $(n=250)$ [21], and $17.5 \%(n=40)$ [9] of Egyptian, Mexican, Chinese, and Brazilian milk samples, respectively, in which were found concentrations 
of up to $3.54 \mu \mathrm{g} / \mathrm{L}$. These results were of particular concern because of the lack of regulation and considering that AFB1 was a recognized human carcinogen [3]. As far as the European milk samples were concerned, up to now, the occurrence of AFB1 had not been reported in the milk samples. The absence of AFB1 that was found in these analyzed Italian milk samples were in agreement with previous studies that were conducted in samples from Spain $[20,23]$. These results seemed to be also related to the maximum AFB1 level that was allowed in the complete feeding stuffs for dairy animals, which was set at $5 \mu \mathrm{g} / \mathrm{kg}$ by Commission Directive 2003/100/EC.

Table 3. Simultaneous occurrence of AFB1 and AFM1 in milk samples, reported in literature.

\begin{tabular}{|c|c|c|c|c|c|c|}
\hline Milk Origin & \multicolumn{2}{|c|}{ Positive Samples } & $\begin{array}{c}\text { \% Positive } \\
\text { Samples }\end{array}$ & $\begin{array}{l}\text { Range } \\
(\mu g / L)\end{array}$ & LOQ $(\mu \mathrm{g} / \mathrm{L})$ & References \\
\hline \multirow{2}{*}{ Mexico } & AFM1 & $117 / 290$ & 1.4 & $<\mathrm{LOQ}-8.35$ & 0.05 & \multirow{2}{*}{ Carvajal et al. [33] } \\
\hline & AFB1 & $4 / 290$ & 40.3 & $<$ LOQ-0.42 & 0.05 & \\
\hline \multirow{2}{*}{ Egypt } & AFM1 & $11 / 80$ & 13.8 & $0.144-0.378$ & n.r. & \multirow{2}{*}{ Nassib et al. [32] } \\
\hline & AFB1 & $1 / 80$ & 1.2 & $<$ LOQ-3.54 & n.r. & \\
\hline \multirow{2}{*}{ Brazil } & AFM1 & $21 / 40$ & 52.5 & $0.7-1.5$ & 0.50 & \multirow{2}{*}{ Scaglioni et al. [18] } \\
\hline & AFB1 & $7 / 40$ & 17.5 & $0.8-1.7$ & 0.25 & \\
\hline \multirow{2}{*}{ Spain } & AFM1 & $0 / 10$ & - & $<$ LOD & 0.025 & \multirow{2}{*}{ Flores-Flores et al. [23] } \\
\hline & AFB1 & $0 / 10$ & - & $<\mathrm{LOD}$ & 0.020 & \\
\hline \multirow{2}{*}{ Spain } & AFM1 & 0/191 & - & $<$ LOD & 0.025 & \multirow{2}{*}{ Flores-Flores et al. [20] } \\
\hline & AFB1 & 0/191 & - & $<\mathrm{LOD}$ & 0.020 & \\
\hline \multirow{2}{*}{ China } & AFM1 & $11 / 45$ & 24.4 & $<\mathrm{LOQ}-0.03$ & 0.01 & \multirow{2}{*}{ Zhou et al. [16] } \\
\hline & AFB1 & $0 / 45$ & - & $<\mathrm{LOD}$ & 0.01 & \\
\hline \multirow{2}{*}{ China } & AFM1 & $247 / 250$ & 98.8 & $0.002-0.028$ & 0.001 & \multirow{2}{*}{ Mao et al. [21] } \\
\hline & AFB1 & $31 / 250$ & 12.4 & $<$ LOQ-0.023 & 0.0033 & \\
\hline \multirow{2}{*}{ Italy } & AFM1 & $0 / 40$ & - & $<$ LOD & 0.002 & \multirow{2}{*}{ This study } \\
\hline & AFB1 & $0 / 40$ & - & $<\mathrm{LOD}$ & 0.002 & \\
\hline
\end{tabular}

\section{Conclusions}

Nowadays, a large number of studies regarding the occurrence of AFM1 in milk are available in the literature. However, there is limited information on the contamination of milk with AFB1, which could be found in this food matrix because of its incomplete metabolism. The present study was conducted to produce a sensitive, rapid, and accurate method in order to determine AFB1 and its metabolite AFM1 in milk. The determination of the studied analytes in a Q-Orbitrap system working in AIF mode, allowed an accurate determination of even ultratrace levels of mycotoxins because of the HRMS analyzer. It was, together with the use of an easy and cheap extraction procedure and the benefits from its application, the most important feature of this analytical procedure. Satisfactory results in terms of linearity, trueness, precision, specificity, and sensitivity were obtained, which fulfilled the requirements that were set by the Commission Decision 2002/657/EC. In addition, the validated method was applied to 40 milk samples. Despite the absence of AFs reported in the herein analyzed samples, the levels of these natural toxins should be continuously monitored to assess their exposure in the global population, as well as in susceptible groups such as children.

Author Contributions: A.R., J.M., and Y.R.C. conceived and designed the experiments; L.I. performed the experiments; G.G. and A.G. analyzed the data; and Y.R.C. wrote the paper.

Acknowledgments: The authors thank the financial support provided by the Spanish Ministry of Economy and Competitiveness (AGL2016-77610-R). Y. Rodríguez-Carrasco thanks the postdoctoral grant, Atracció de Talent, which was provided by the University of Valencia.

Conflicts of Interest: The authors declare no conflict of interest. 


\section{References}

1. Bhat, R.; Rai, R.V.; Karim, A.A. Mycotoxins in food and feed: Present status and future concerns. Compr. Rev. Food Sci. Food Saf. 2010, 9, 57-81. [CrossRef]

2. Food and Agriculture Organization. Worldwide Regulations for Mycotoxins in Food and Feed in 2003, 2004. Available online: www.fao.org/docrep/007/y5499e/y5499e00.htm (accessed on 17 April 2018).

3. International Agency for Research on Cancer. Agents Classified by the IARC Monographs; IARC: Lyon, France, 2012; Volume 1, p. 103.

4. Commission Directive 2003/100/EC of 31 October 2003 Amending Annex I of Directive 2002/32/EC of the European Parliament and of the Council on Undesirable Substances in Animal Feed. 2003. Available online: https: / / eur-lex.europa.eu/eli/dir/2003/100/oj (accessed on 4 April 2018).

5. International Agency for Research on Cancer, IARC. Evaluation of carcinogenic risks of chemical to humans. In Some Naturally-Occurring Substances: Food Items and Constituents; Heterocyclic Aromatic Amines and Mycotoxins; IARC: Lyon, France, 1993; Volume 56, p. 245.

6. Ketney, O.; Santini, A.; Oancea, S. Recent aflatoxin survey data in milk and milk products: A review. Int. J. Dairy Technol. 2017, 320-331. [CrossRef]

7. Commission Regulation (EU) No 165/2010 of February 2010 Amending Regulation (EC) No 1881/2006 Setting Maximum Levels for Certain Contaminants in Foodstuffs as Regards Aflatoxins. 2010. Available online: https:/ / eur-lex.europa.eu/legal-content/EN/ALL/?uri=CELEX\%3A32010R0165 (accessed on 4 April 2018).

8. Food and Agriculture Organization Food Balance Sheet. 2013. Available online: http://www.fao.org/ faostat/en/\#data/FBS (accessed on 17 April 2018).

9. Chen, C.Y.; Li, W.J.; Peng, K.Y. Determination of Aflatoxin M1 in Milk and Milk Powder Using High-Flow Solid-Phase Extraction and Liquid Chromatography-Tandem Mass Spectrometry. J. Agric. Food Chem. 2005, 53, 8474-8480. [CrossRef] [PubMed]

10. Bognanno, M.; La Fauci, L.; Ritieni, A.; Tafuri, A.; De Lorenzo, A.; Micari, P.; Galvano, F. Survey of the occurrence of Aflatoxin M1 in ovine milk by HPLC and its confirmation by MS. Mol. Nutr. Food Res. 2006, 50, 300-305. [CrossRef] [PubMed]

11. Zinedine, A.; González-Osnaya, L.; Soriano, J.M.; Moltó, J.C.; Idrissi, L.; Mañes, J. Presence of aflatoxin M1 in pasteurized milk from Morocco. Int. J. Food Microbiol. 2007, 114, 25-29. [CrossRef] [PubMed]

12. Frenich, A.G.; Romero-González, R.; Gómez-Pérez, M.L.; Vidal, J.L.M. Multi-mycotoxin analysis in eggs using a QuEChERS-based extraction procedure and ultra-high-pressure liquid chromatography coupled to triple quadrupole mass spectrometry. J. Chromatogr. A 2011, 1218, 4349-4356. [CrossRef] [PubMed]

13. Tolosa, J.; Graziani, G.; Gaspari, A.; Chianese, D.; Ferrer, E.; Mañes, J.; Ritieni, A. Multi-Mycotoxin Analysis in Durum Wheat Pasta by Liquid Chromatography Coupled to Quadrupole Orbitrap Mass Spectrometry. Toxins 2017, 9, 59. [CrossRef] [PubMed]

14. Yogendrarajah, P.; Van Poucke, C.; De Meulenaer, B.; De Saeger, S. Development and validation of a QuEChERS based liquid chromatography tandem mass spectrometry method for the determination of multiple mycotoxins in spices. J. Chromatogr. A 2013, 1297, 1-11. [CrossRef] [PubMed]

15. Rodríguez-Carrasco, Y.; Fattore, M.; Albrizio, S.; Berrada, H.; Mañes, J. Occurrence of Fusarium mycotoxins and their dietary intake through beer consumption by the European population. Food Chem. 2015, 178, 149-155. [CrossRef] [PubMed]

16. Zhou, J.; Xu, J.J.; Cong, J.M.; Cai, Z.X.; Zhang, J.S.; Wang, J.L.; Ren, Y.P. Optimization for quick, easy, cheap, effective, rugged and safe extraction of mycotoxins and veterinary drugs by response surface methodology for application to egg and milk. J. Chromatogr. A 2018, 1532, 20-29. [CrossRef] [PubMed]

17. Rubert, J.; León, N.; Sáez, C.; Martins, C.P.B.; Godula, M.; Yusà, V.; Mañes, J.; Soriano, J.M.; Soler, C. Evaluation of mycotoxins and their metabolites in human breast milk using liquid chromatography coupled to high resolution mass spectrometry. Anal. Chim. Acta 2014, 820, 39-46. [CrossRef] [PubMed]

18. Scaglioni, P.T.; Becker-Algeri, T.; Drunkler, D.; Badiale-Furlong, E. Aflatoxin B1 and M1 in milk. Anal. Chim. Acta 2014, 829, 68-74. [CrossRef] [PubMed]

19. Sahin, H.Z.; Celik, M.; Kotay, S.; Kabak, B. Aflatoxins in dairy cow feed, raw milk and milk products from Turkey. Food Addit. Contam. Part B 2016, 9, 152-158. [CrossRef] [PubMed] 
20. Flores-Flores, M.E.; González-Peñas, E. Short communication: Analysis of mycotoxins in Spanish milk. J. Dairy Sci. 2018, 101, 113-117. [CrossRef] [PubMed]

21. Mao, J.; Zheng, N.; Wen, F.; Guo, L.; Fu, C.; Ouyang, H.; Lei, S. Multi-mycotoxins analysis in raw milk by ultra high performance liquid chromatography coupled to quadrupole orbitrap mass spectrometry. Food Control 2018, 84, 305-311. [CrossRef]

22. Tsiplakou, E.; Anagnostopoulos, C.; Liapis, K.; Haroutounian, S.A.; Zervas, G. Determination of mycotoxins in feedstuffs and ruminant's milk using an easy and simple LC-MS/MS multiresidue method. Talanta 2014, 130, 8-19. [CrossRef] [PubMed]

23. Flores-Flores, M.E.; González-Peñas, E. An LC-MS/MS method for multi-mycotoxin quantification in cow milk. Food Chem. 2017, 218, 378-385. [CrossRef] [PubMed]

24. Jia, W.; Chu, X.; Ling, Y.; Huang, J.; Chang, J. Multi-mycotoxin analysis in dairy products by liquid chromatography coupled to quadrupole Orbitrap mass spectrometry. J. Chromatogr. A 2014, 1345, 107-114. [CrossRef] [PubMed]

25. Rodríguez-Carrasco, Y.; Izzo, L.; Gaspari, A.; Graziani, G.; Mañes, J.; Ritieni, A. Urinary levels of enniatin B and its phase I metabolites: First human pilot biomonitoring study. Food Chem. Toxicol. 2018, 118, 454-459. [CrossRef] [PubMed]

26. European Commission Decision (2002/657/EC) of 12 August 2002 Implementing Council Directive 96/23/EC Concerning the Performance of Analytical Methods and Interpretation of Results. 2002. Available online: https:/ publications.europa.eu/en/publication-detail/- / publication/ed928116-a9554a84-b10a-cf7a82bad858/language-en (accessed on 4 April 2018).

27. Konieczka, P.; Namieśnik, J. Estimating uncertainty in analytical procedures based on chromatographic techniques. J. Chromatogr. A 2010, 1217, 882-891. [CrossRef] [PubMed]

28. Boudra, H.; Barnouin, J.; Dragacci, S.; Morgavi, D.P. Aflatoxin M1 and ochratoxin A in raw bulk milk from French dairy herds. J. Dairy Sci. 2007, 90, 3197-3201. [CrossRef] [PubMed]

29. Bilandžić, N.; Varenina, I.; Solomun, B. Aflatoxin M1 in raw milk in Croatia. Food Control 2010, 21, $1279-1281$. [CrossRef]

30. Duarte, S.C.; Almeida, A.M.; Teixeira, A.S.; Pereira, A.L.; Falcão, A.C.; Pena, A.; Lino, C.M. Aflatoxin M1 in marketed milk in Portugal: Assessment of human and animal exposure. Food Control 2013, 30, 411-417. [CrossRef]

31. Flores-Flores, M.E.; Lizarraga, E.; de Cerain, A.L.; González-Peñas, E. Presence of mycotoxins in animal milk: A review. Food Control 2015, 53, 163-176. [CrossRef]

32. Nassib, T.A.; Guergues, S.N.; Motawee, M.M. Survey for Detection and Determination of Aflatoxins M1 and B1 in local Milk and Certain Dairy Products by Thin Layer Chromatographic Method. Egypt. J. Hosp. Med. 2005, 18, 29-36.

33. Carvajal, M.; Rojo, F.; Méndez, I.; Bolaños, A. Aflatoxin B1 and its interconverting metabolite aflatoxicol in milk: The situation in Mexico. Food Addit. Contam. 2003, 20, 1077-1086. [CrossRef] [PubMed]

(C) 2018 by the authors. Licensee MDPI, Basel, Switzerland. This article is an open access article distributed under the terms and conditions of the Creative Commons Attribution (CC BY) license (http://creativecommons.org/licenses/by/4.0/). 